\title{
Quench sensitivity of toughness in an Al alloy: direct observation and analysis of failure initiation at the precipitate free zone
}

\author{
T.F. Morgeneyer ${ }^{\mathrm{a}, 1,2}$, M.J. Starink ${ }^{\mathrm{b}, 1}$, S.C. Wang ${ }^{\mathrm{c}, 1}$ and I.Sinclair ${ }^{\mathrm{d}, 1}$ \\ ${ }^{1}$ Materials Research Group, School of Engineering Sciences, University of Southampton, \\ Southampton, SO17 1BJ, United Kingdom \\ ${ }^{2}$ Alcan Centre de Recherches de Voreppe, BP 27, 38341 Voreppe Cedex, France \\ a tm504@soton.ac.uk, ${ }^{b}$ m.j.starink@soton.ac.uk, ${ }^{c}$ wangs@soton.ac.uk ${ }^{d}$, i.sinclair@soton.ac.uk
}

\begin{abstract}
Analysis of toughness in $6156 \mathrm{Al}-\mathrm{Mg}-\mathrm{Si}-\mathrm{Cu}$ sheet has been performed using enhanced Kahn tear tests on samples quenched at different rates. Crack initiation energies were hardly affected by changing water quench temperature from $20^{\circ} \mathrm{C}$ to $60^{\circ} \mathrm{C}$; however a significant reduction was evident on air cooling. Crack propagation energy was reduced for both $60^{\circ} \mathrm{C}$ water quenched and air cooled materials. Observation of failure initiation through synchrotron radiation computed tomography (SRCT), for the $60^{\circ} \mathrm{C}$ water quenched material revealed failure ahead of the crack tip of grain boundaries oriented at $45^{\circ}$ to the main loading axis and crack "tongues" extending into the material ahead of the main crack. Failure was predominantly intergranular. Fractographic assessment revealed predominantly voiding and shear decohesion in the $20^{\circ} \mathrm{C}$ water quenched material. With the aid of the new findings past models on the influence of precipitate free zone parameters on toughness have been revised.
\end{abstract}

\section{Introduction}

The toughness reduction caused by the presence of a precipitate free zone (PFZ) adjacent to the grain boundaries is a limiting factor for application of a range of heat treatable Al based alloys. Whilst past work has investigated the process through post failure analysis of toughness test samples and some basic ideas of the influence of precipitate zone width, grain boundary coverage and local strength have been proposed [1,2,3], a full analysis that is able to encompass all the main aspects including deformation geometry, stress partitioning and failure initiation has proved elusive, and no details on failure initiation sites have been reported. Current synchrotron radiation computed tomography (SRCT) resolution capabilities (resolution better than $1 \mu \mathrm{m}$ ) allows for direct 
visualisation of microstructure and fracture micromechanisms within a material bulk in three dimensions (3D) [4]. As such it now allows detailed assessment of fracture mechanisms and the evolution of damage. In order to gain a novel insight into the changes of fracture mechanisms of materials with a PFZ, this paper reports the application of the technique to arrested cracks, allowing the evolution of damage and coalescence of damage at the crack tip to be imaged in 3D. Additionally, via the application and diffusion of gallium into the samples, it is possible to delineate grain boundaries in SRCT [5]: the facility to image samples with and without treatment allows for detailed correlation of fracture processes to the underlying grain structure.

The material to be studied is an AA6156 Al-Si-Mg-Cu alloy, which has recently been developed for its combination of high strength aluminium and weldability, which makes it suitable for airframe applications [6]. AA6X56 Al-Si-Mg-Cu alloys display good weldability, low density, good corrosion resistance and equivalent mechanical properties to established damage tolerant alloys such AA2024, and hence may be considered as potential replacements. Such AA6X56 alloys contain relatively high solute levels which can contribute to quench sensitivity [7], and, in common with a range of other $6 \mathrm{XXX}$ alloys, PFZs develop at grain boundaries of quenched and aged alloys. In damage tolerant applications, toughness will be a critical factor in design, and therefore accurate understanding of the mechanisms causing quench sensitivity with respect to toughness are of interest [8].

It is well established that different quench rates affect mechanical properties such as yield strength, ultimate tensile strength and fracture toughness in age hardened Al-alloys. However, fracture toughness may be substantially more quench sensitive than yield strength [9]. The mechanisms for changes in mechanical properties due to quench sensitivity in $\mathrm{Al}-\mathrm{Mg}-\mathrm{Si}$ alloys have been attributed to the precipitation of coarse phases on grain boundaries $[10,11]$ and dispersoids $[12,13]$, and to solute and/or vacancy depletion in zones around those nucleation sites forming soft precipitate free zones after ageing. It has been reported that the precipitation of coarse phases on grain boundaries along with the formation of a PFZ may result in a change of fracture mode from transgranular to intergranular fracture decreasing the fracture toughness of the material $[10,11]$. Attempts have been made to model and predict quench effects on hardness involving quench factor analysis [13].

The microstructural changes responsible for changes in toughness are characterised here by transmission electron microscopy (TEM) and SRCT. With the aid of the new findings past models on the influence of precipitate free zone parameters on toughness will be revised. 


\section{Experimental}

AA6156 sheet was supplied by Alcan CRV. The AA composition ranges are given in Table 1 . Optical micrographs of the grain structure after etching with Keller's etch are shown in Fig. 1.

Samples of $3.2 \mathrm{~mm}$ thickness were solutionised at $550^{\circ} \mathrm{C}$ for $30 \mathrm{~min}$. Quenching was then carried out into: (a) water at $20^{\circ} \mathrm{C}$, (b) water at $60^{\circ} \mathrm{C}$, or (c) still lab air. The delay between solutionizing and quenching was very short (less than 1s). Cooling rates in plates of $3 \mathrm{~mm}$ thickness for the 3 relevant cooling procedures are given in Table 2 (data from Hatch [14]). (All rates refer to the average rate over $400^{\circ} \mathrm{C}$ to $290^{\circ} \mathrm{C}$.) All three types of sample were subsequently subjected to a heating ramp of $20^{\circ} \mathrm{C} / \mathrm{h}$ up to $190^{\circ} \mathrm{C}$ where they were held for $4 \mathrm{~h}$, reaching a peak age (T6) condition. Kahn tear tests are performed under displacement control in general accord with [15].

Field emission gun scanning electron microscope (JEOL 6500F) images were used to assess material microstructures and subsequent fracture surfaces. Transmission electron microscopy (JEOL 3010) was also carried out: samples were prepared by cutting thin slices $(\sim 0.3 \mathrm{~mm})$ from the quenched and aged samples, punched into $3 \mathrm{~mm}$ diameter discs and ground to a thickness of $\sim 0.2$ $\mathrm{mm}$. Subsequent electropolishing was performed with a twin jet electropolisher using a solution of $30 \% \mathrm{HNO}_{3}$ and $70 \%$ methanol maintained between $-20^{\circ} \mathrm{C}$ and $-30^{\circ} \mathrm{C}$.

For the SRCT assessment cracks were grown in Kahn tear test [15] pieces to a length of 10mm (arrested before final failure of the coupon). A small block of material (dimensions 1 x 1 x $10 \mathrm{~mm}^{3}$ ) was then extracted at the crack tip region using a slow speed diamond saw: as such, subsequent tomographic scanning of the crack itself could be carried out, as well as the material immediately ahead of the arrested tip. SRCT was performed at $20 \mathrm{kV}$ at beamline ID19 of the ESRF, Grenoble, France. The facility provides a highly coherent, spatially and spectrally homogeneous beam with a high photon flux. The typical imaging time was $0.7 \mathrm{sec}$. For one volume 1500 radiographs were taken using a high performance CCD camera and simultaneously the sample was turned $180^{\circ}$ in steps of $0.12^{\circ}$. Flat-field and dark current corrections were performed and reconstruction was carried out using a conventional filtered back projection algorithm [5]. In the reconstructed slices an isotropic voxel size of $0.7 \mu \mathrm{m}$ was obtained. Phase contrast imaging has been performed allowing to enhance the detection of edges [16]. At the beamline ID19 this is a straightforward technique as advantage is taken of the radiation coherence by adjusting the sample detector distance ( $13 \mathrm{~mm}$ in the present work) to obtain near-field Fresnel diffraction effects. Detailed information about the imaging techniques is given in [17].

Scans were carried out for both the 'as tested' crack tip samples, and after subsequent liquid gallium $(\mathrm{Ga})$ grain boundary wetting [18], allowing the grain boundaries and their relationship to the fracture process to be imaged in three dimensions. 2D and 3D visualisation and analysis of the 
SRCT data was performed via the commercial software package VG Studio Max, v1.2 (Volume Graphics Gmbh), with selected 2D sections being presented here.

\begin{tabular}{ccccccc}
\hline $\mathrm{Si}$ & $\mathrm{Fe}$ & $\mathrm{Cu}$ & $\mathrm{Mn}$ & $\mathrm{Mg}$ & $\mathrm{Cr}$ & $\mathrm{Zn}$ \\
\hline $0.7-1.3$ & $<0.2$ & $0.7-1.1$ & $0.4-0.7$ & $0.6-1.2$ & $<0.25$ & $0.1-0.7$ \\
\hline
\end{tabular}

Table 1: Composition limits of alloy AA6156 alloy in wt \%

\begin{tabular}{cccc}
\hline Quenching & $\begin{array}{c}\text { to water at room } \\
\text { temperature (RT): }\end{array}$ & to water at $60^{\circ} \mathrm{C}$ & in still air \\
\hline Quench rate & $1000^{\circ} \mathrm{C} / \mathrm{s}$ & $205^{\circ} \mathrm{C} / \mathrm{s}$ & $0.94^{\circ} \mathrm{C} / \mathrm{s}$ \\
\hline
\end{tabular}

Table 2: Quench rates of plate of 3mm thickness (after [14] )

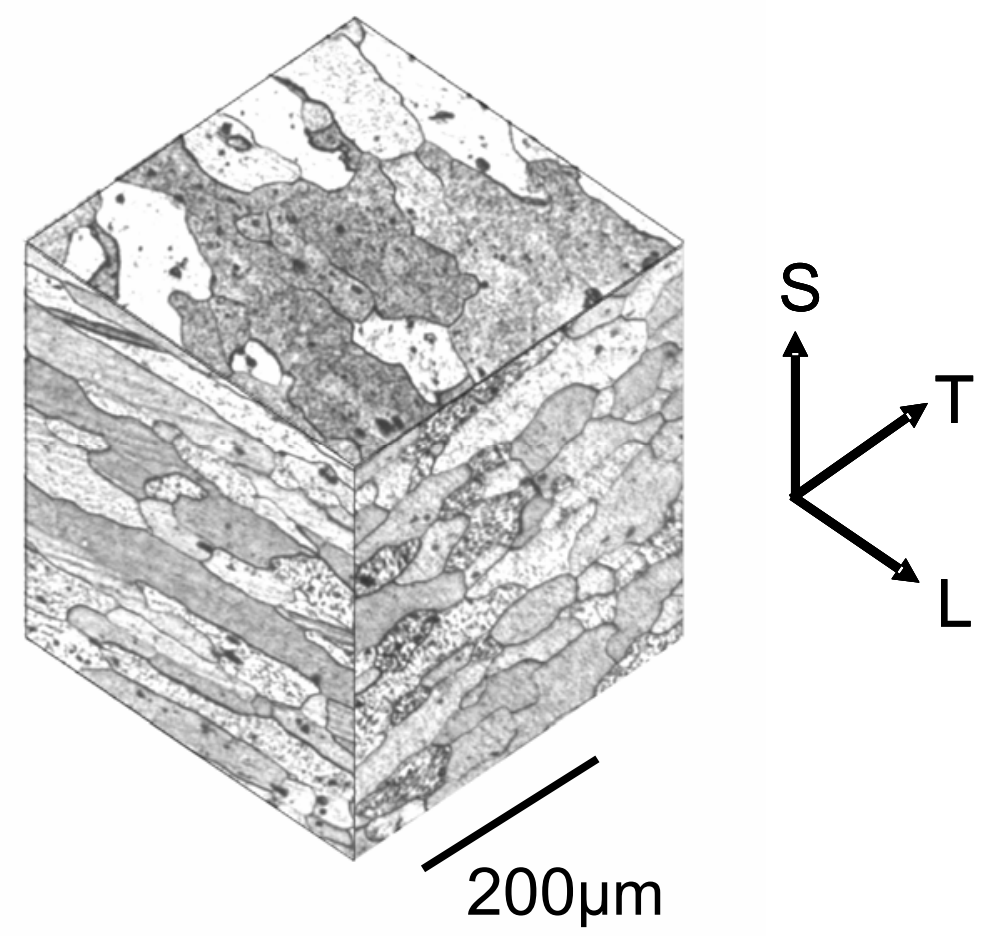

Fig. 1: Pseudo three-dimensional optical micrograph in T3 condition 


\section{Results}

\section{TEM}

Despite the fast quench, $20^{\circ} \mathrm{C}$ water-quenched samples exhibited precipitate free zones (PFZs) at the grain boundaries, along with some particle decoration of the boundaries, see Fig. 2(a). PFZ total width was seen to vary between 40 and $70 \mathrm{~nm}$ in the water quenched samples. For the slower quench rate of $60^{\circ} \mathrm{C}$ water quench, quench-induced precipitation becomes more apparent (see Fig. 2(b)), with a substantial increase in grain boundary particle coverage with a moderate increase in PFZ width (to $\sim 80-100 \mathrm{~nm}$ ). In the air-cooled material, the quench induced precipitates are seen to decorate the majority of the observed grain boundary areas, with a PFZ width of $\sim 400 \mathrm{~nm}$ being discerned (see Fig. 2(c)). Based on boundary views in thin regions of the available TEM samples, and estimating sample thickness using thickness fringes, the grain boundary coverage levels for the quench conditions were estimated as 0.08 and 0.09 for the $20^{\circ} \mathrm{C}$ quench and the $60^{\circ} \mathrm{C}$ quench materials. With an estimated accuracy of about 0.02 , there is not sufficient proof to determine a significant difference. The grain boundary coverage of the air-cooled material proved variable but is significantly higher.

No significant quench-induced heterogeneous precipitation was identified on dispersoid particles for the $20^{\circ} \mathrm{C}$ and $60^{\circ} \mathrm{C}$ water-quenched samples. The $60^{\circ} \mathrm{C}$ water-quenched material showed evidence for a very limited PFZ around the dispersoid particles, however the usually curved morphology of the dispersoid particles made clear identification of a small PFZ difficult. Large elongated particles ( $\sim 500 \mathrm{~nm}$ in length) were clearly seen on the dispersoids of the air cooled material, surrounded by a substantial PFZ (see Fig. 3).

The diameter of hardening precipitates was of the order of several nanometers (Fig. 2(a)). Selected area diffraction (SAD) patterns in [100] directions (not presented here) were essentially similar for the two types of water quenched samples with streaks, and local maxima on the streaks that are consistent with patterns previously reported for alloys with similar compositions [19].

\section{Kahn Tear Testing}

In the Kahn tear tests, the crack length and applied force $F$ were measured as a function of crack tip mouth opening displacement (CMOD). Typical data are shown in Fig. 4, showing both crack length and $F / A_{0}$ (where $A_{0}$ is the initial uncracked ligament area) as a function of CMOD.

The peak nominal stresses of the $20^{\circ} \mathrm{C}$ water quenched and the $60^{\circ} \mathrm{C}$ water quenched materials are very similar. The unit initiation energy (UIE, defined as the integral $\int F / A_{0} \mathrm{~d} l_{d}$, where $\mathrm{d} l_{d}$ is the pin displacement, taken from the start of the test to maximum load) decreases by $\sim 15 \%$ between the 
$20^{\circ} \mathrm{C}$ and $60^{\circ} \mathrm{C}$ water quenched materials, but drops more significantly for the air cooled material (see Table 3). After achieving the maximum nominal stress, crack propagation stresses are lower for the $60^{\circ} \mathrm{C}$ water quenched material as compared to the $20^{\circ} \mathrm{C}$ quenched materials at the same CMOD. For the air cooled material, crack propagation occurs at loads that are always lower than the water quenched materials; the initial nominal stresses as well as the nominal stresses during crack propagation are markedly reduced. The crack also grows faster for much of the test (as a function of CMOD) in the air cooled material than in the water cooled materials, indicative of substantially reduced toughness.
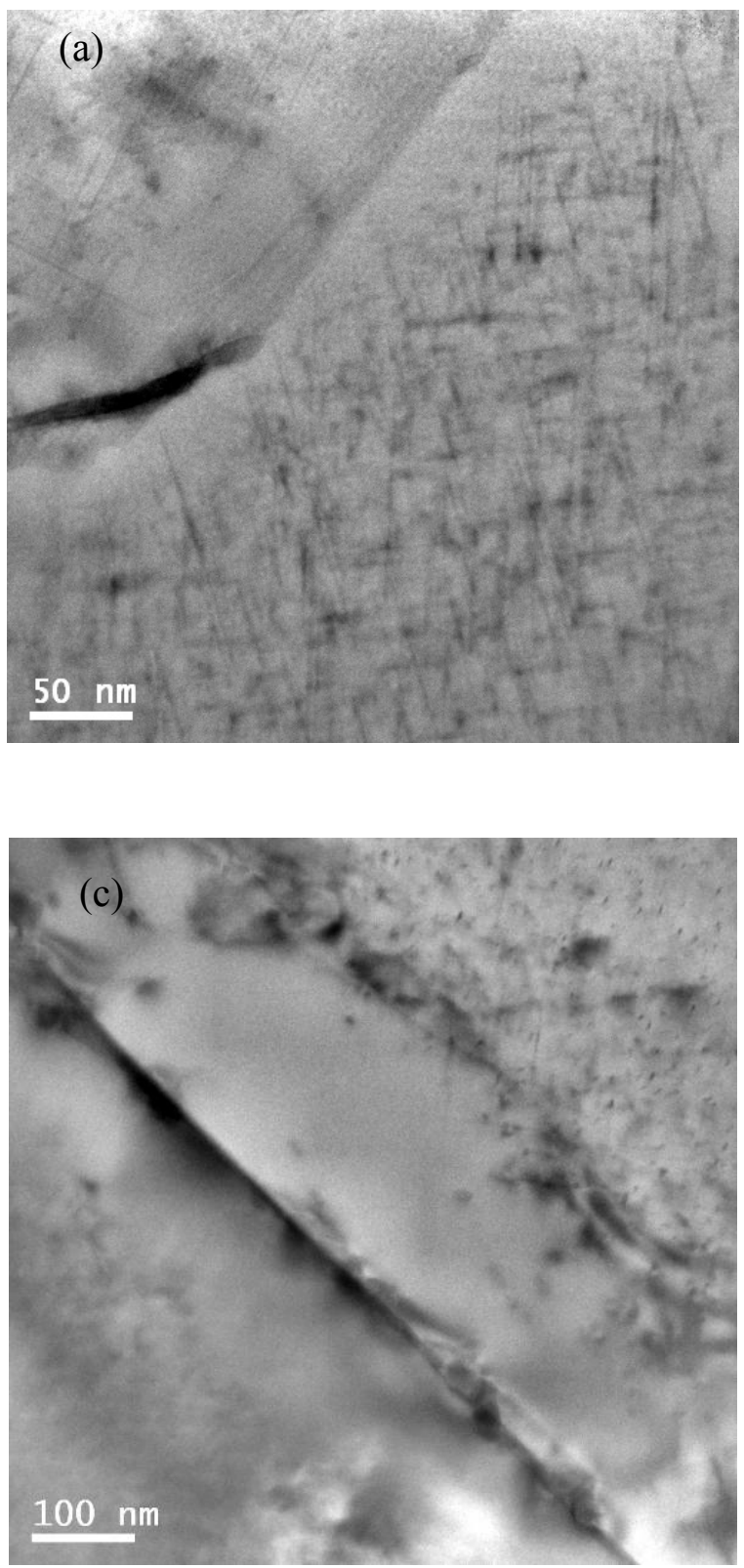

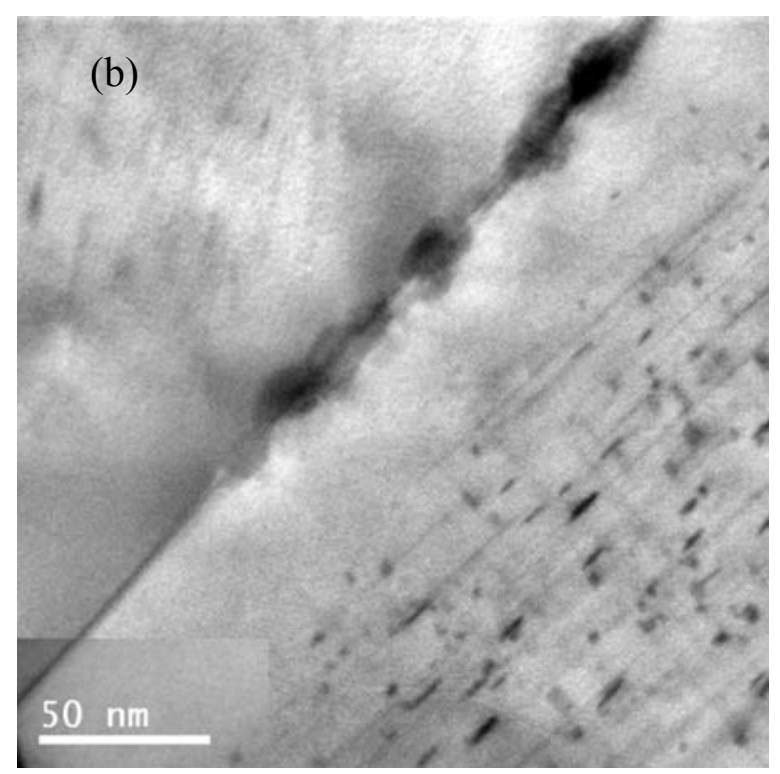

Fig. 2: TEM micrographs of intergranular precipitates after (a) $20^{\circ} \mathrm{C}$ water quench and ageing, (b) $60^{\circ} \mathrm{C}$ water quench and ageing (c) air cool and ageing 


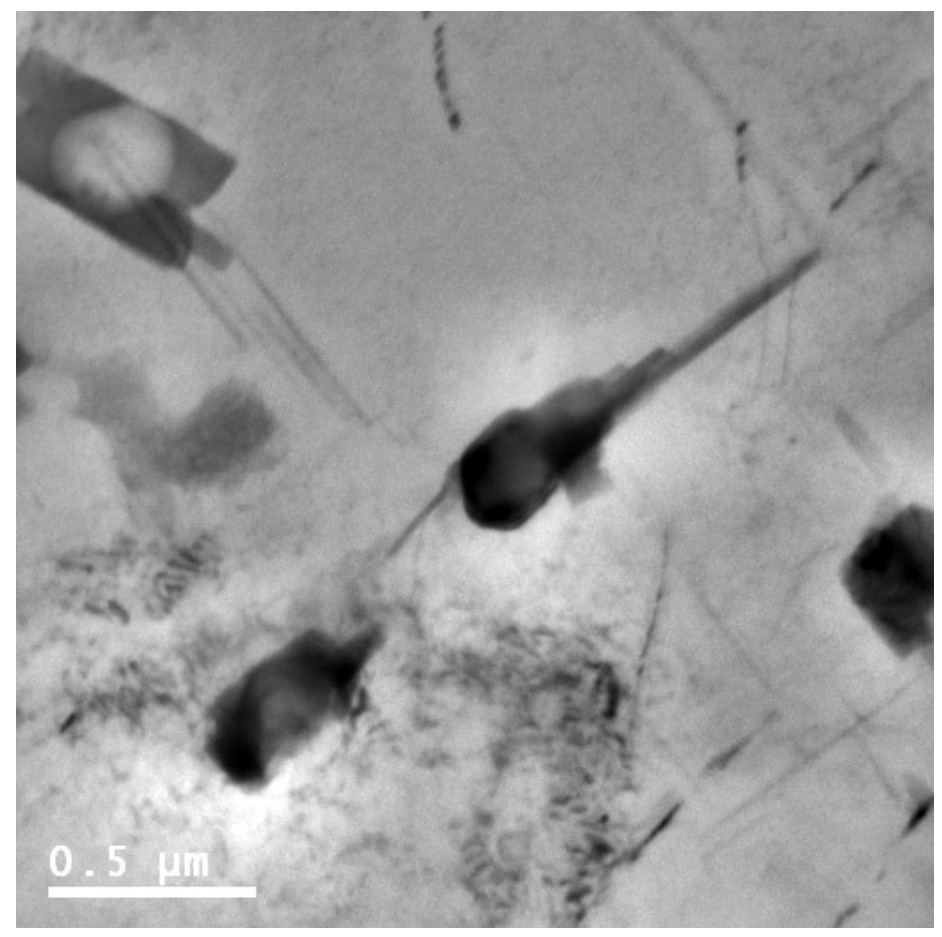

Fig. 3: TEM micrograph of dispersoids (dark, equiaxed particles) after air cooling and ageing. Note the large elongated particles that nucleated on the dispersoids, with a zone devoid of the fine precipitates around them.

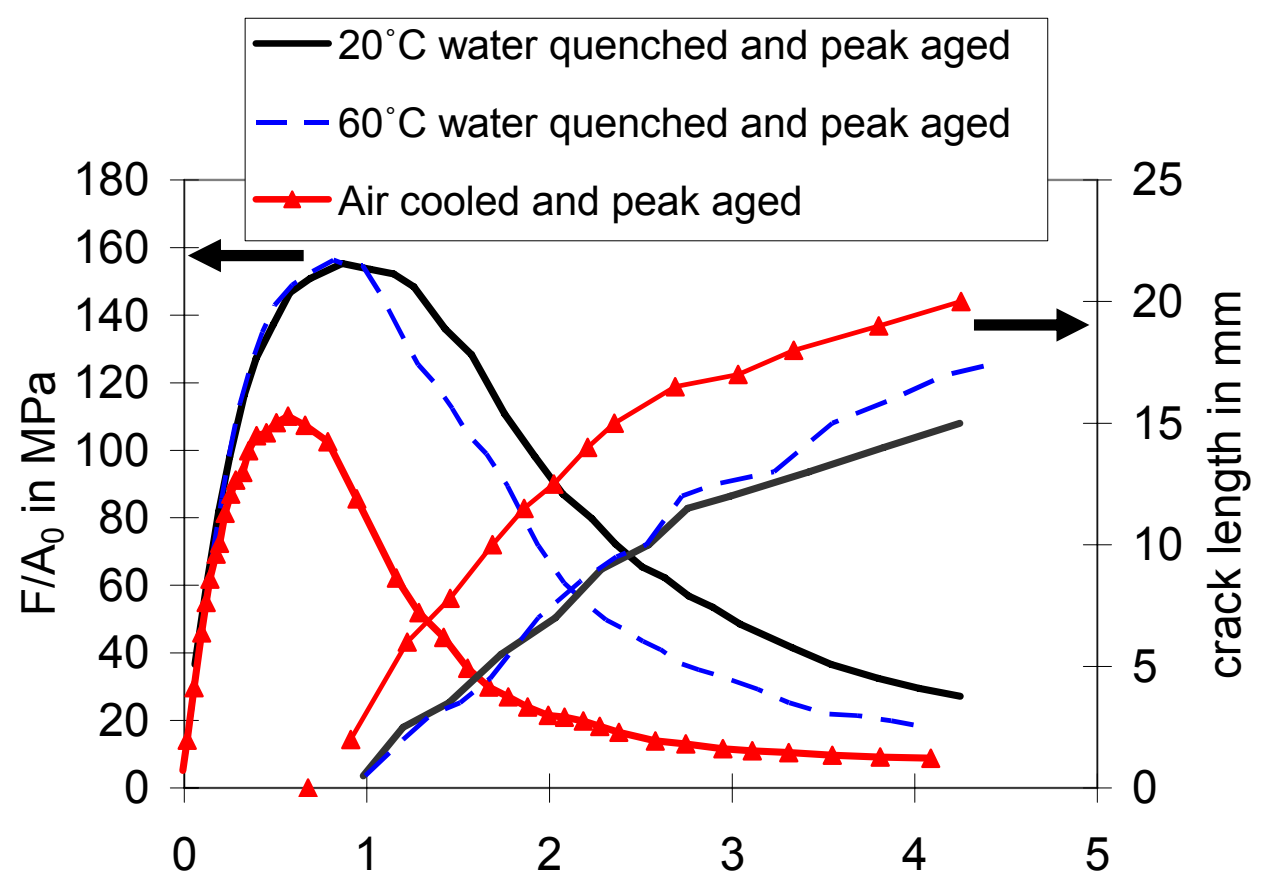

Fig. 4: Kahn tear test results: nominal stress $\left(F / A_{0}\right)$ and crack length versus crack mouth opening displacement for different quench rates.

Crack mouth opening displacement (CMOD) in $\mathrm{mm}$ 


\section{Fractography}

On a macroscopic scale, the fractured tear test samples show an approximately triangular region where the crack surface is normal to the main tensile axis, followed by a transition to a slant $\left(\sim 45^{\circ}\right)$ fracture mode. This is consistent with the evolution of the triaxial constraint conditions [20]: in the triangular region high stress triaxiality is encountered during crack initiation, whilst increasing plastic zone size as the crack propagates leads to a loss of constraint and hence to a decreased triaxility (see also [21]). Fig. 5 shows SEM images of typical fracture surfaces of the three samples at the triangular region of crack growth, as indicated in Fig. 5(d). Fig. 5(a) shows a detailed image of a typical fracture surface region of the $20^{\circ} \mathrm{C}$ water quenched material; coarse voiding is the prevailing feature in this case (void diameters of the order of $10-40 \mu \mathrm{m}$ ). The voids are evidently associated with coarse second phase particles, with a relatively small amount of final coalescence via finer, secondary void formation. Similar to the $20^{\circ} \mathrm{C}$ water quenched material, coarse voiding is generally prevalent in the $60^{\circ} \mathrm{C}$ water quenched material, see Fig. 5(b) however, there are also aligned, finer featured regions, exhibiting small, shallow voids (diameters of the order of $1 \mu \mathrm{m}$ ). With ongoing crack growth into the slant fracture regions for both water quenched conditions, an increasing propensity for locally slant fracture was noted, with a marked reduction in the proportion of coarse voiding. In Fig. 5(c), typical of the air cooled samples, aligned intergranular features are evident, covering the majority of the fracture surfaces. Evidence of ductile failure is seen at larger intermetallic particles on the fracture surface; however void growth is apparently limited by the onset of the intergranular failure. The failure morphology of the air cooled material is consistent with classical intergranular ductile failure and is seen to be dominant in both macroscopically flat and slant regions of the fracture surfaces [22].

Fig. 6 shows SEM images of the fracture surface at $15 \mathrm{~mm}$ from the notch at mid-thickness, in the macroscopically slant region. On the fracture surface of the $20^{\circ} \mathrm{C}$ water quenched material (Fig. 6(a)) there is relatively high coverage of coarse voids; however there are some additional regions which are planar, tilted and covered with fine dimples, consistent with shear decohesion. Again, the fracture surface of the $60^{\circ} \mathrm{C}$ water quenched material shows similar features to the $20^{\circ} \mathrm{C}$ water quenched material; however elongated apparently intergranular features are also evident (identification of intergranular failure is considered in further detail in the next section). The fracture surface of the air cooled material appears essentially similar to that in the macroscopically flat region; there are few coarse voids and a predominantly intergranular morphology is seen exhibiting fine dimples. 

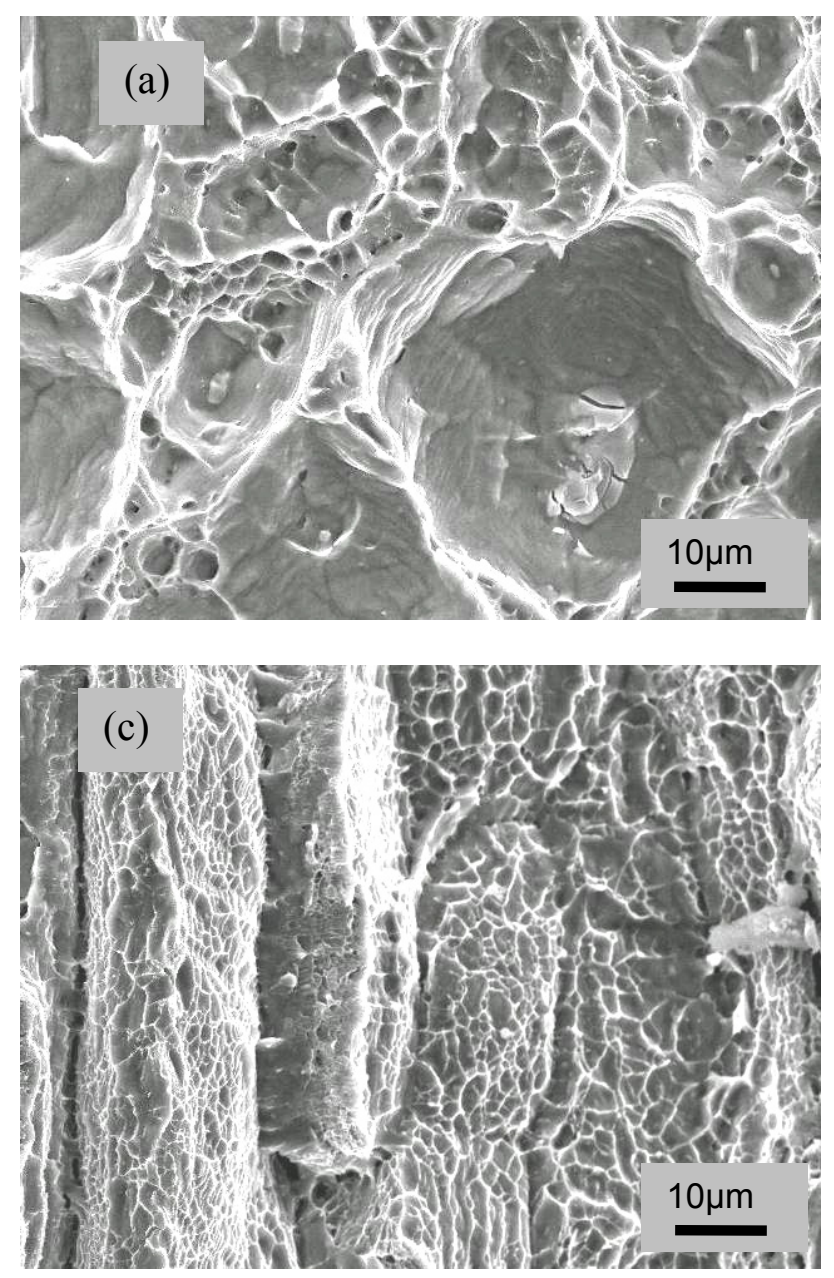

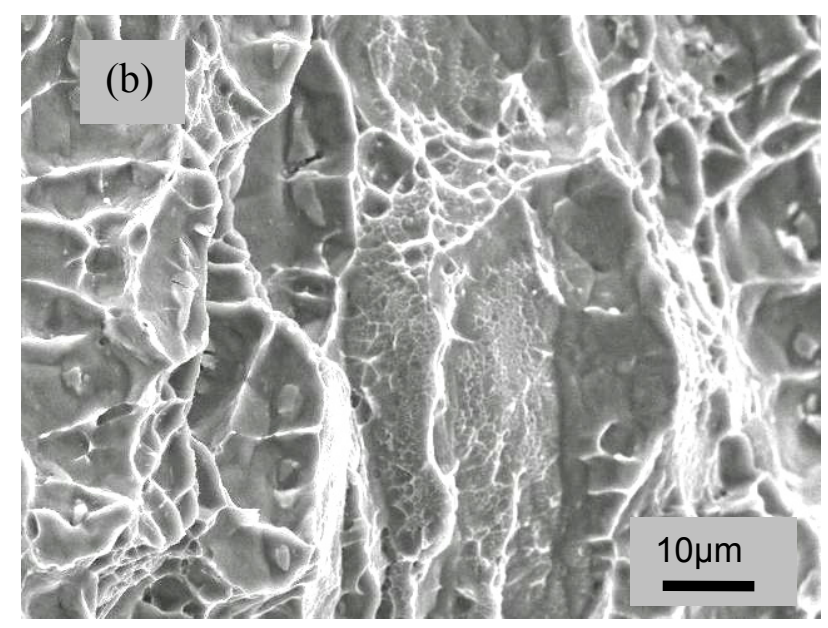

(d)

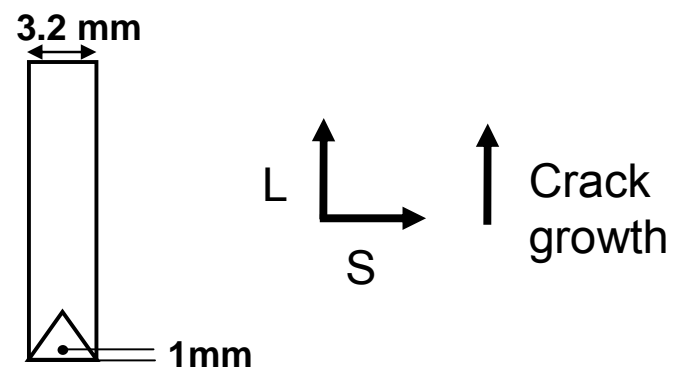

Fig. 5: SEM micrographs (secondary electron mode) of the fracture surface at mid-thickness $1 \mathrm{~mm}$ from the notch of (a) the $20^{\circ} \mathrm{C}$ water quenched and peak aged material, (b) the $60^{\circ} \mathrm{C}$ water quenched and peak aged material, (c) the air cooled and peak aged material. A schematic illustration of macroscopic fracture surface regions and position of the images is shown in (d).

\section{Tomography}

Tomography scans of the arrested cracks offer the opportunity to observe the actual initiation of failure and the evolution of the fracture process. Fig. 7 shows 2D tomography sections of the crack in the $60^{\circ} \mathrm{C}$ water quenched material before and after the gallium wetting (Fig 7(a) and (b) respectively) with the crack growth direction normal to the section. The aluminium matrix (grey), intermetallics (white) and pores, as well as the crack (black), are clearly delineated, with the phase contrast fringes highlighting the associated edges/interfaces. In Fig. 7(b) the grain boundaries can additionally be seen in white due to the local segregation of gallium. Fig. 7(a) reveals crack areas that are oriented in the loading direction (running up and down the page in Fig. 7) and other parts that are inclined with respect to the loading direction. There are regions of increased crack opening consistent with the presence of coarse voids along the crack. Comparing the crack in the gallium 
wetted sample to the sample before gallium wetting indicates that much of the crack path follows grain boundaries. This is particularly evident for the parts of the crack that are oriented in the loading direction, but is also evident for areas that are inclined with respect to the loading direction.
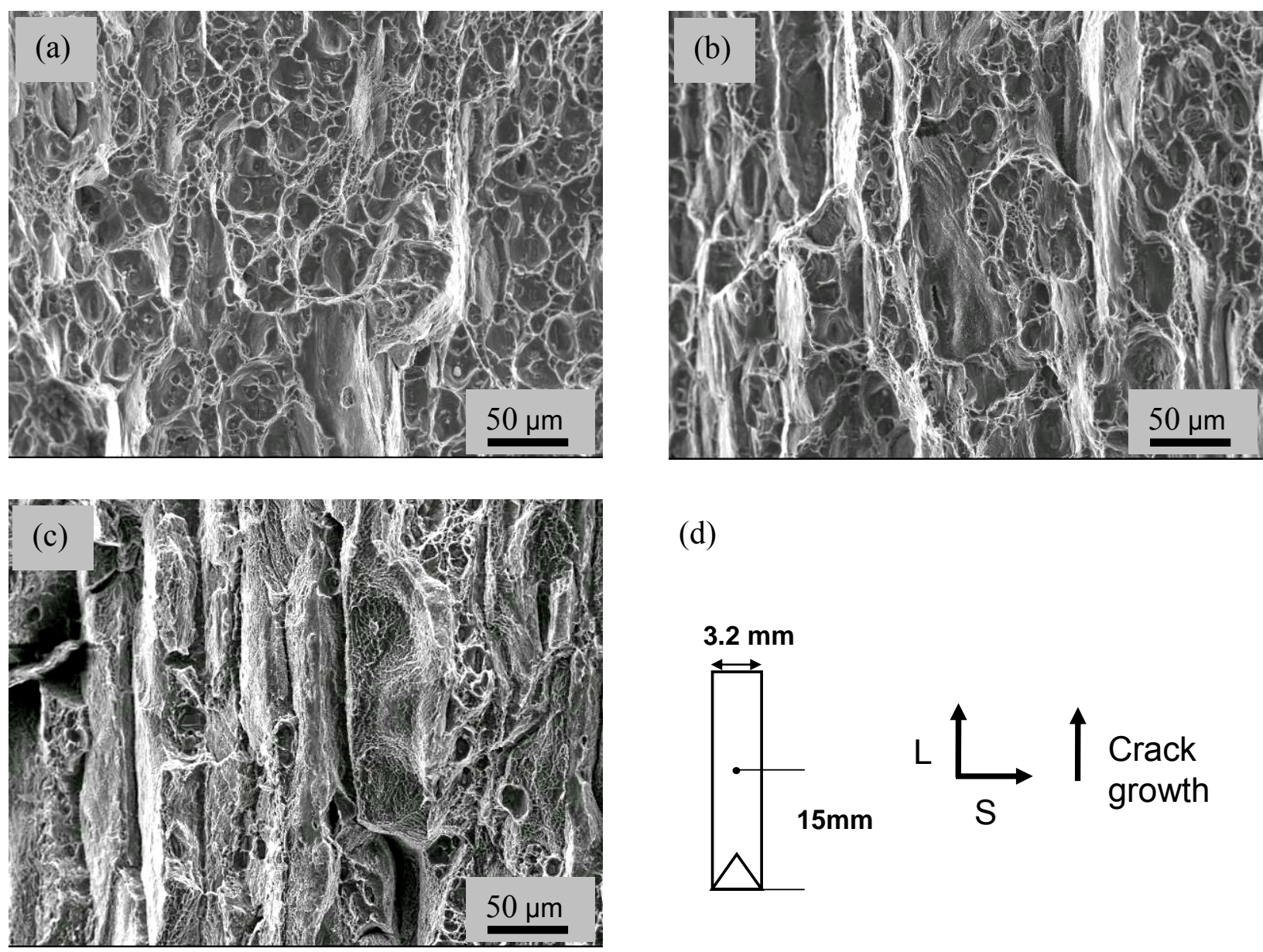

(d)

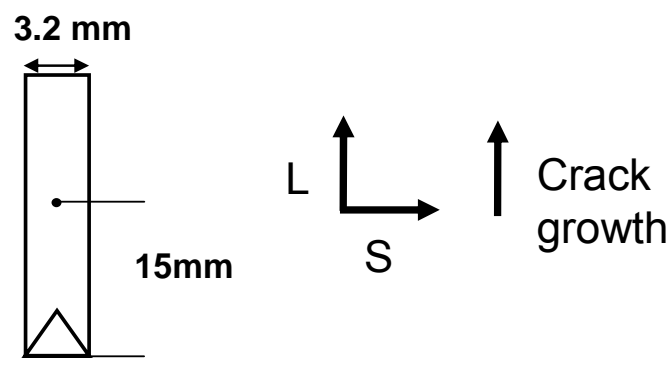

Fig. 6: SEM micrographs of the fracture surface at mid-thickness at 15mm from the notch of (a) the $20^{\circ} \mathrm{C}$ water quenched and peak aged material, (b) $60^{\circ} \mathrm{C}$ water quenched and peak aged material, and (c) air cooled and peak aged material. A schematic illustration of macroscopic fracture surface regions and position of the images is shown in (d).

An exact quantification of the fraction of crack running along the grain boundary is however difficult as both the crack surface and grain boundaries are gallium wetted and thus both appear white (scanning the grain structure of the sample before tearing is not possible by this technique as only small parts of the Kahn tear test sample can be scanned at this resolution and the Gallium wetting embrittles the sample dramatically).

Fig. 8(a) shows damage at the very crack tip of the $60^{\circ} \mathrm{C}$ water quenched material before gallium wetting, whilst Fig. 8(b) again shows the same location after the gallium treatment. Fig. 8(a) shows a combination of coarse voids from intermetallic particles and relatively narrow cracks/voids that 
are inclined with respect to the loading direction. The narrow regions are seen to be disconnected with each other in the through-thickness direction, i.e. the crack tip is distinctly ligamented with crack "tongues" extending into the material ahead of the main crack. Considering Fig. 8(b) it becomes clear that the narrow, tilted regions all lie on grain boundaries inclined to the loading direction.

\section{Loading direction}
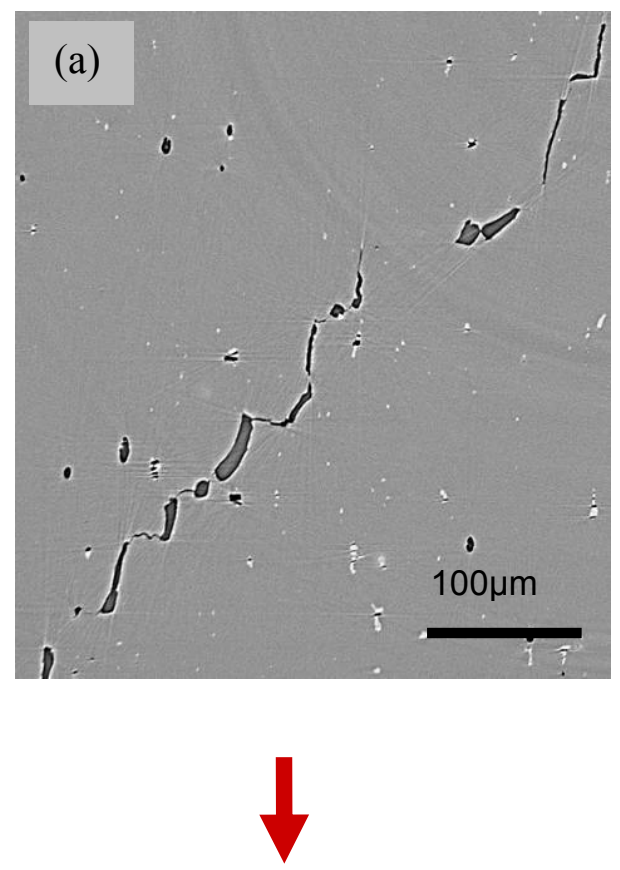
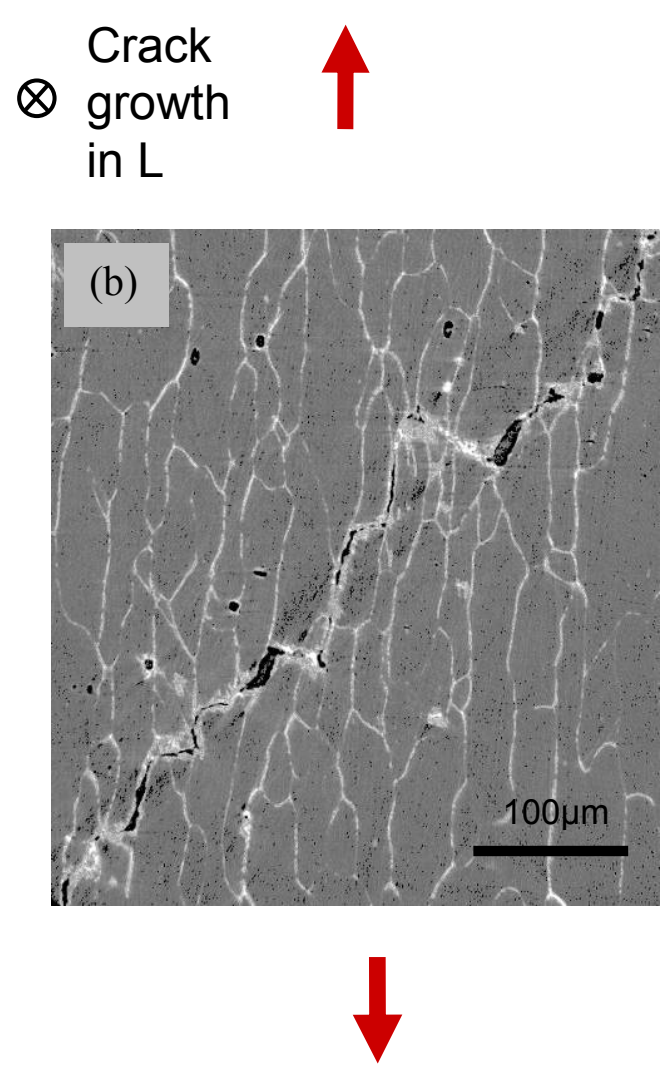

Fig. 7: 2D section of tomography data showing the crack in the $60^{\circ} \mathrm{C}$ water quenched material (a) without gallium wetting, and (b) after gallium wetting.

From the observations in Fig.s 7 and 8, it may be seen that the initiation and coalescence of damage into a contiguous crack in the $60^{\circ} \mathrm{C}$ quenched material occur by a combination of coarse voiding and intergranular failure along tilted sections of the grain boundary structure. Additionally small tilted cracks that are independent from coarse voids or initial porosity and the main crack plane were identified in the material ahead of the crack tip, as exemplified by the crack in the upper left quadrant of Fig. 8(a) seen to be at some distance (about $100 \mu \mathrm{m}$ ) from the main crack plane. Fig. 9 highlights another such independent crack exhibiting a ' $\mathrm{V}$ '-shape morphology; comparison of the sections obtained from scans without and without gallium wetting shows these independent cracks invariably lie on inclined grain boundaries. Many of such distinct crack initiation sites have been identified in the scanned volumes of the $60^{\circ} \mathrm{C}$ quenched material $\left(50-60\right.$ per $\mathrm{mm}^{3}$ in the region up 
to $\sim 1 \mathrm{~mm}$ from the crack tip), all of which where associated with boundaries inclined between 35 and $55^{\circ}$ to the load direction.

\section{个 Loading direction}
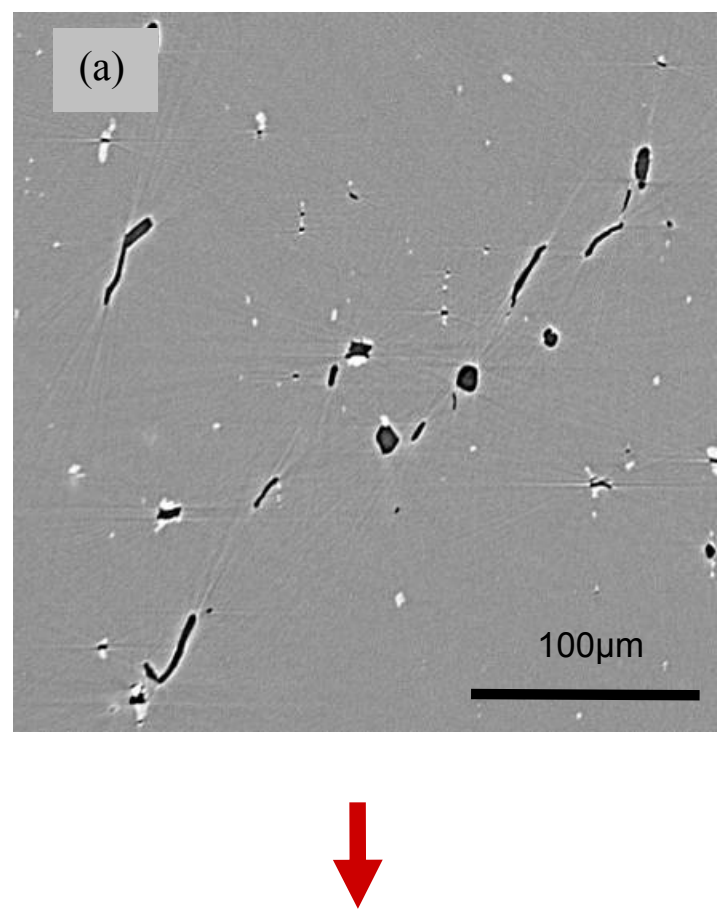
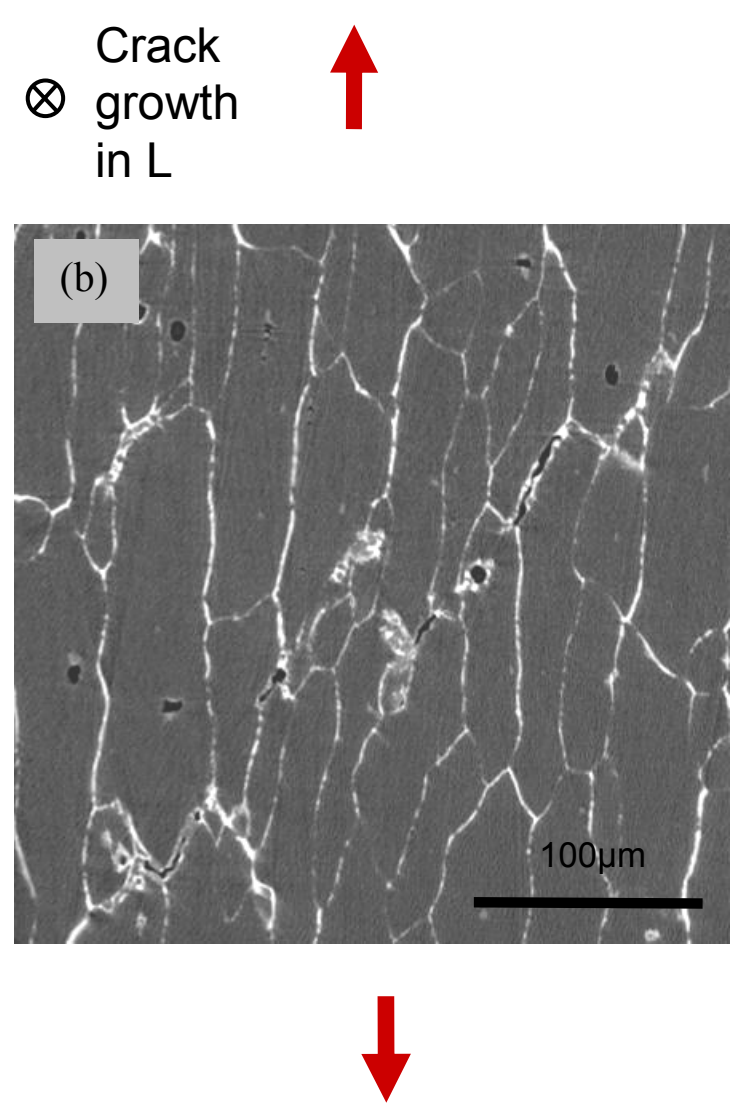

Fig. 8: $2 \mathrm{D}$ section of tomography data showing the crack tip in the $60^{\circ} \mathrm{C}$ water quenched material (a) without gallium wetting, and (b) after gallium wetting.

Fig. 10 shows sections of fracture in the $20^{\circ} \mathrm{C}$ water quenched material both in the main crack and the near tip region. The crack tip in this case is more dominated by regions of coarse void coalescence, with few of the inclined crack 'tongues' of the $60^{\circ} \mathrm{C}$ quench material. Furthermore very few independent tilted crack sections are seen ahead of the main crack.

Fig. 11 shows failure in the air cooled material before and after gallium wetting. Most of the crack opening is very narrow for this condition. There is little coarse voiding discernable, consistent with the SEM observation. Comparing the section before and after gallium wetting it appears that the fracture path is highly intergranular in nature. A significant difference with respect to the water quenched materials is the high proportion of cracking (along grain boundaries) in the loading direction (see left-hand side of Fig. 11(a)). 


\section{$\uparrow$ Loading direction $\otimes$ grack 4 growth in $\mathrm{L}$}
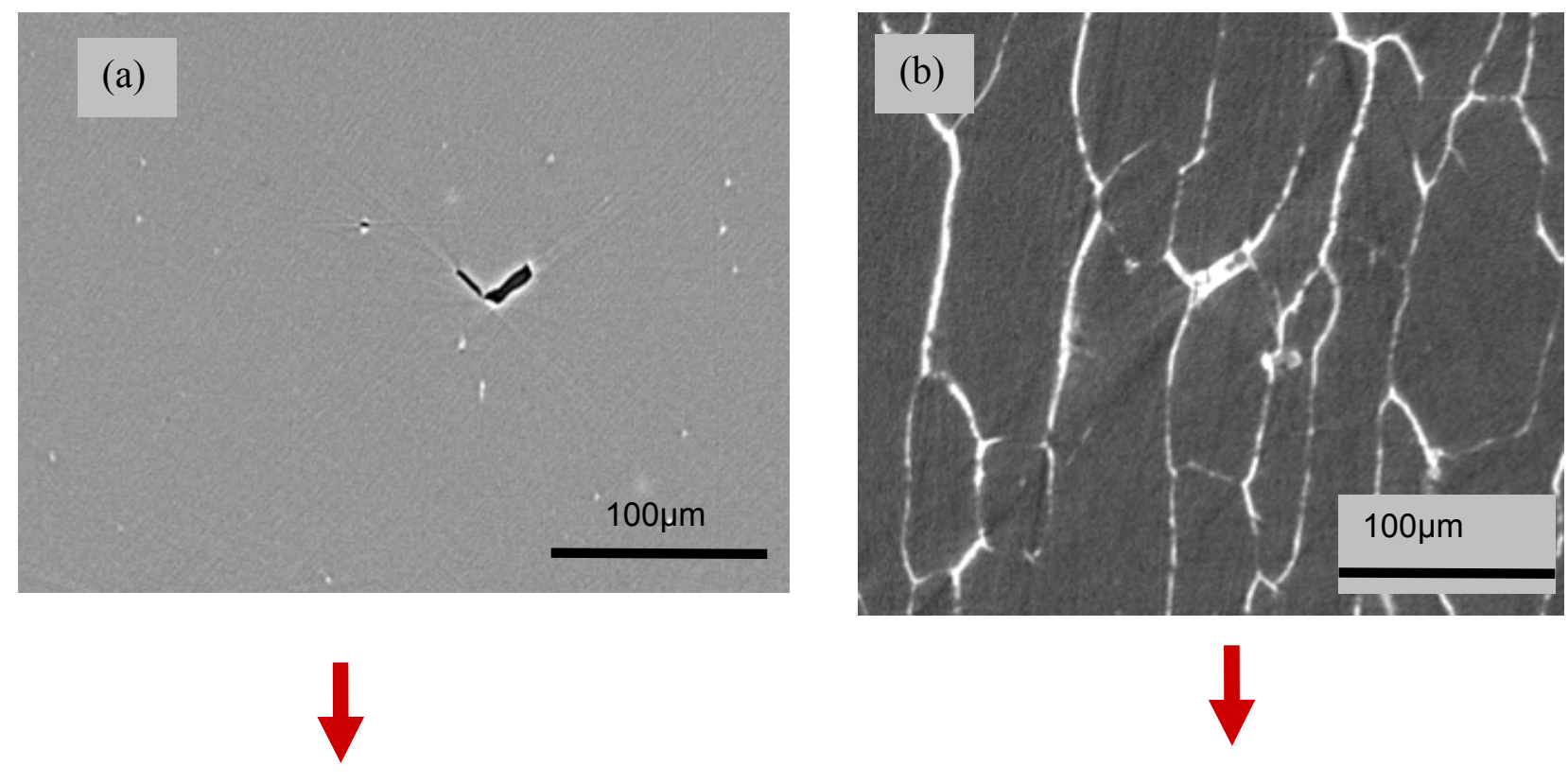

Fig. 9: $2 \mathrm{D}$ section of $v$-shaped narrow crack in the $60^{\circ} \mathrm{C}$ water quenched material (a) without gallium, and (b) after gallium wetting.
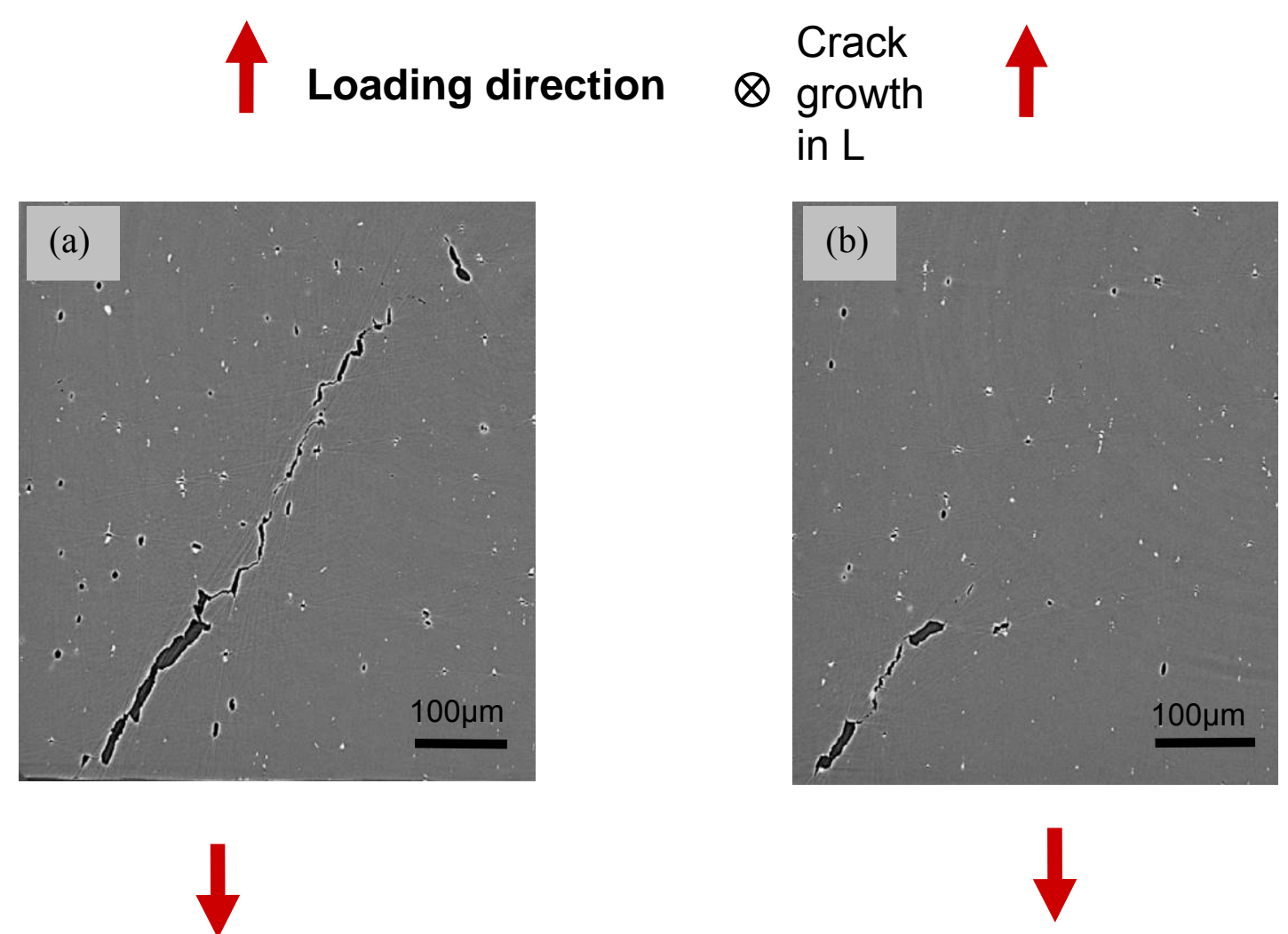

Fig. 10: $20^{\circ} \mathrm{C}$ water quenched material: (a) $2 \mathrm{D}$ section of tomography data showing the main crack, and (b) 2D section of tomography data showing damage at the crack tip. 


\section{Loading direction $\underset{\substack{\text { Crack } \\ \text { in } L}}{\text { growth }} \mathbf{1}$}
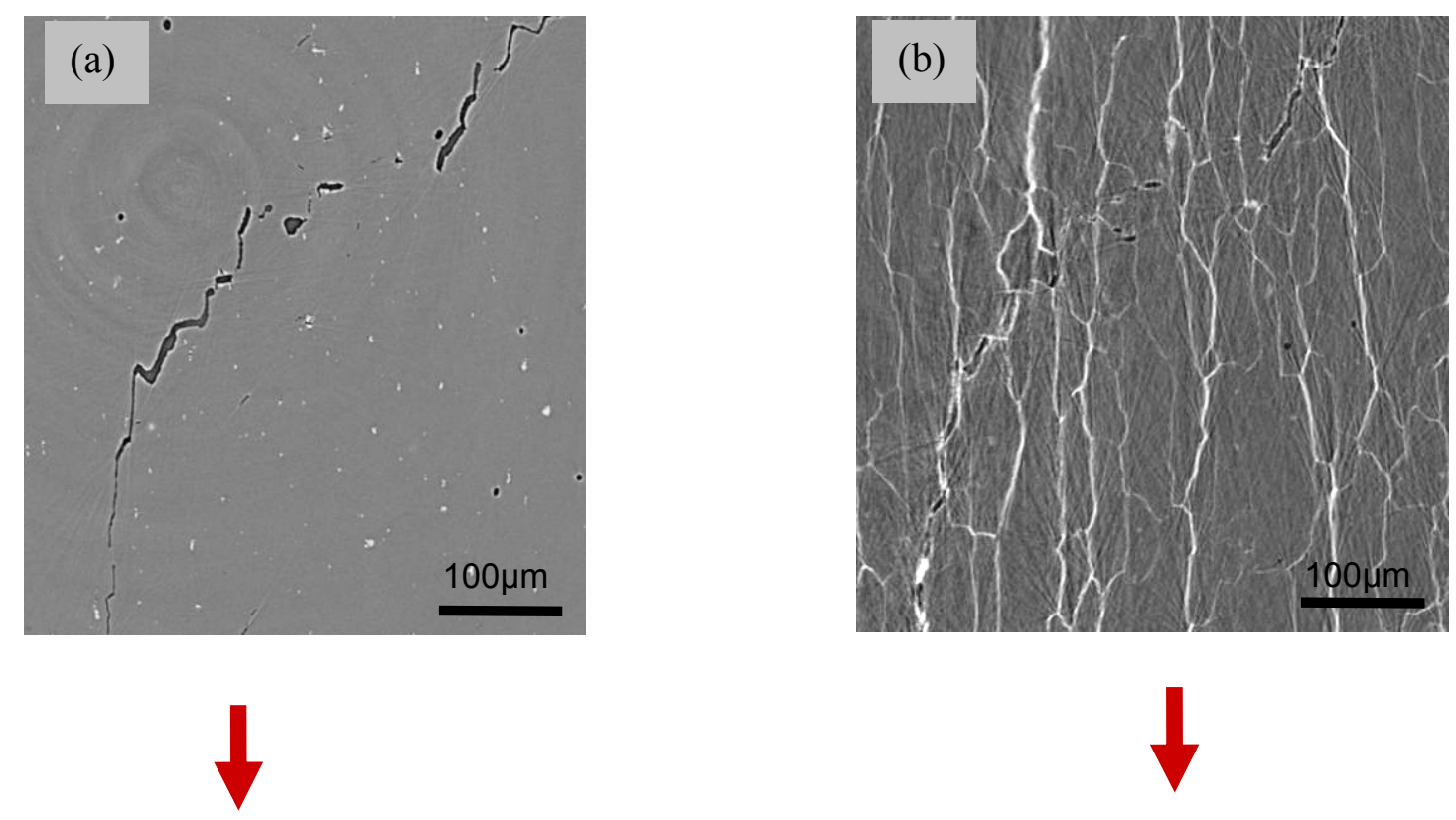

Fig. 11: 2D section of tomography data of the air cooled material showing the crack (a) before the gallium wetting, and (b) after the gallium wetting.

\section{Loading direction}
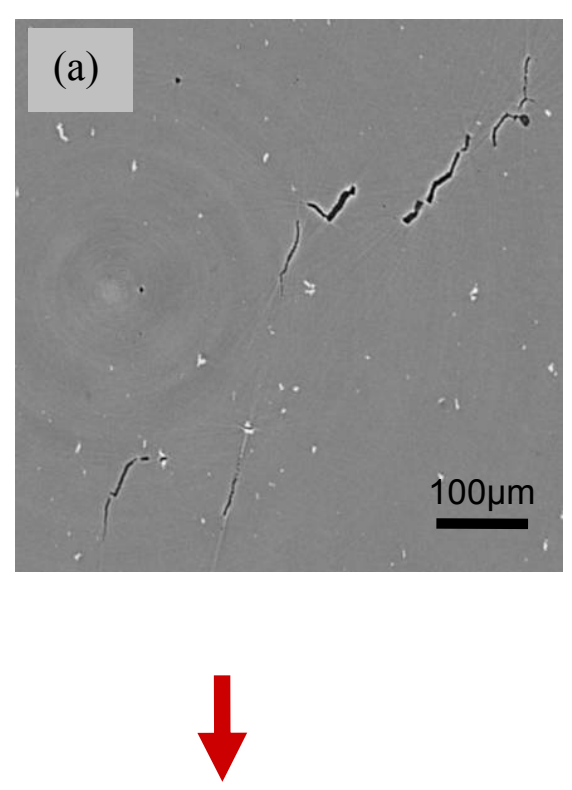
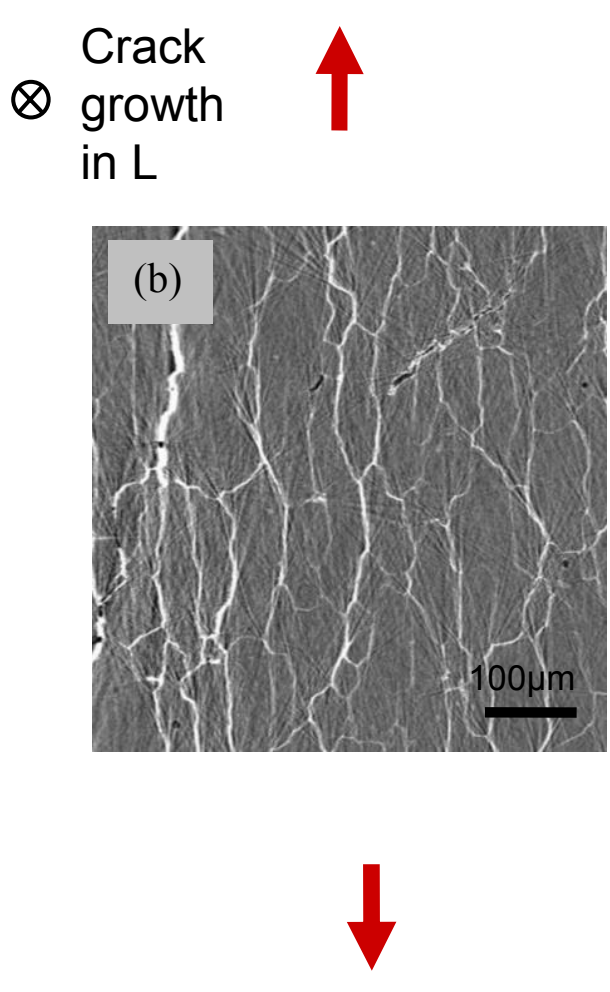

Fig. 12: 2D section of tomography data of the air cooled material showing the crack tip:

(a) before gallium wetting, and (b) after gallium wetting. 
Fig. 12 shows a 2D section close to the crack tip in the air cooled material. The tip is narrow, and also ligamented, but to a lesser extent than in the $60^{\circ} \mathrm{C}$ water quenched material $(\sim 5$ ligaments $/ \mathrm{mm}$ crack width for the air cooled material compared to $\sim 20$ ligaments $/ \mathrm{mm}$ crack width for the $60^{\circ} \mathrm{C}$ water cooled material). There is one independent crack visible in Fig. 12 that lies on a grain boundary; overall however there were few independent crack sites apparent in the air cooled material ( $\sim 1-10$ single cracks $/ \mathrm{mm}^{3}$ within $\sim 1 \mathrm{~mm}$ of the crack tip for the air cooled material, compared to $\sim 50-60$ independent cracks $/ \mathrm{mm}^{3}$ for the $60^{\circ} \mathrm{C}$ water quenched material).

\section{Discussion}

\section{Microstructure - strength - toughness relations}

Differential Scanning Calorimetry (DSC) data on the present materials [23] indicates that alloying elements precipitate partially during the slower cooling treatments considered here. The changes in the DSC curves between the $20^{\circ} \mathrm{C}$ and $60^{\circ} \mathrm{C}$ water quenched material are however small compared to the dramatic changes with respect to the $-200^{\circ} \mathrm{C}$ DSC cooled material and the air cooled material [23]. The hardness is not significantly affected by the slower water quench, whilst it is reduced by $\sim 10 \%$ for the air cool. Similar changes in tensile behaviour between water and air quenching have been identified in Refs. [10,11] for an Al-Mg-Si-Cu alloy and been attributed to particle decoration and the formation of a wide PFZ at grain boundaries similar to that seen in this work. In addition, the significant PFZ around dispersoids with large precipitates formed on them, as evidenced in this work (Fig. 3), is also evidence of the reduction in the amounts of solute.

Hardness and strength have been reported to be less quench sensitive than fracture toughness $[9,24]$ which is consistent with the more volume-averaged nature of bulk plastic flow, as opposed to the localized nature of strain and damage accumulation associated with fracture. The observed combination of grain boundary particle decoration and PFZ formation has been widely discussed in relation to generation of grain boundary ductile failure (e.g. see [9,22,24]), consistent with the present reductions in toughness with reduced quench rates. The tomography studies of arrested cracks carried out in this work revealed clear differences in the fracture mechanisms and the evolution of damage between samples quenched at different rates. In the $60^{\circ} \mathrm{C}$ water quenched material the presence of inclined grain boundary failure both at the crack tip and in the material immediately ahead to the tip indicate a potentially controlling influence of shear localisation in crack initiation at grain boundary PFZs [25] (orientation of maximum shear stress will be close to $45^{\circ}$ with respect to the loading direction under conditions of lower stress triaxiality of the arrested crack sections). Crack propagation in this case proceeds via intergranular areas of narrow crack 
opening ahead of the main crack that are inclined with respect to the loading direction, along with some opening of coarse voids, a number of which appear to develop from the intrinsic pore content of the alloy and therefore may be considered to have no real initiation stage. During crack extension those damage features then grow and ultimately link, particularly via grain boundaries that are oriented close to the loading direction. In the air cooled material it may be seen however that, given the relative absence of independent boundary failures ahead of the main crack, the initiation and coalescence of boundary failure at the crack tip is more simultaneous $\left(c f\right.$. the $60^{\circ} \mathrm{C}$ quench material).

It is difficult to separate the potential contributions to fracture of plastic strain partitioning within the relatively soft PFZ material and local flow strains to failure associated with a high density of void nucleating particles along the grain boundaries [26]. In terms of the present results it is interesting to note that crack growth at high stress triaxiality is evidently less susceptible to quench embrittlement, i.e. crack initiation toughness is hardly reduced by the $60^{\circ} \mathrm{C}$ quench (hardness testing showed no significant change in flow strength between the two water quenched materials, with the implication of essentially equivalent stress state evolution under load for these materials). Increased triaxiality is expected to favour primary void growth [21], although it may be recognised that the plane of maximum shear associated with lower stress triaxiality is more favourably inclined to generate boundary shear in the present aligned grain structure: with the observed correlation of initial grain boundary failure (ahead of the crack) with inclined boundaries, then both factors may contribute to the change in quench sensitivity between the regions with of high and lower stress triaxiality.

\section{Models for toughness in the presence of a PFZ}

In order to predict the influence of microstructural changes due to the varying quench rates an appropriate micromechanical model needs to account for the identified mechanisms of crack initiation and coalescence during failure. Additionally, a distinction between the crack initiation stage (high stress triaxiality) and the crack propagation stage (lower stress triaxiality) needs to be made. In the present study, fracture of the water cooled materials in the flat/high stress triaxiality region is seen to be dominated by coarse voiding and a degree of shear decohesion and/or grain boundary failure, whilst the fracture surface of the air cooled material is dominated by intergranular features and limited coarse voiding. Thus, an appropriate micromechanical toughness model would need to take a multimechanistic approach to analyse these test conditions. Notwithstanding the need for full multimechanistic approach, several works have established models for toughness based on grain boundary dominated fracture (e.g. in Refs. [1,3,27]). The model suggested by Embury and 
Nes [27] for example, considers that all strain is concentrated in the PFZ, and relates plane strain fracture toughness $K_{I C}$ to the grain boundary particle coverage $A_{f}$ :

$$
K_{I C} \sim\left(E \sigma_{R}\left(A_{f}^{-\frac{1}{2}}-1\right) / 2\right)^{\frac{1}{2}}
$$

where $\sigma_{R}$ is close to the ultimate tensile strength. We will here develop a modified treatment that relaxes the assumption that all strain is concentrated in the PFZ and we will instead make the more realistic assumption of constant shear stress across the material.

With reference to the schematic drawing in Fig. 13, consider a material consisting of grain with typical dimension $d_{\mathrm{G}}$, with particles on the grain boundaries covering a fraction $f_{\mathrm{GB}}$ and a PFZ around the grain boundary of full width $d_{\mathrm{PFZ}}$. Consider that all the material is substantially plastically deformed and that the elastic part of the deformation can be neglected. Consider that the relation between shear stress, $\tau_{\mathrm{G}}$ and shear strain $\gamma_{\mathrm{G}}$ of the grain is given by a power law hardening equation:

$$
\tau_{\mathrm{G}}=K_{\mathrm{G}} \gamma_{\mathrm{G}}^{p_{\mathrm{G}}}+\tau_{\mathrm{y}, \mathrm{G}}
$$

where $p_{\mathrm{G}}$ is the strain hardening exponent in the grain and $K_{\mathrm{G}}$ is the strain hardening factor in the grain. We assume that it is sufficiently accurate to describe the PFZ as a zone with homogeneous mechanical properties, and similar to the grains we take the stress-strain relationship as:

Crack
growth

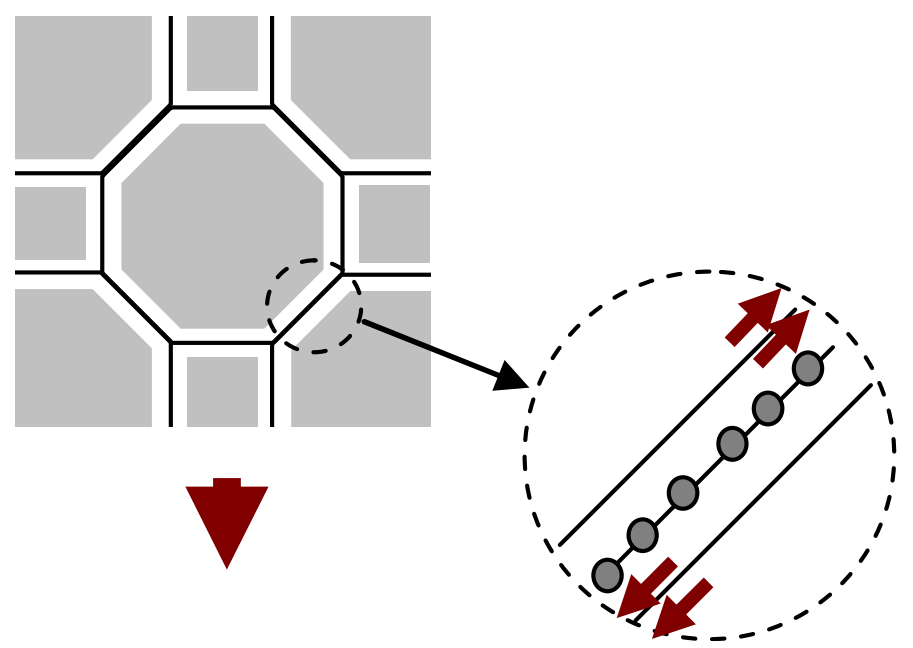

Fig. 13: Schematic illustration of the equi-shear strain model. The grain shape depicted here has no particular meaning: the model does not assume any particular grain shape, other than that it has boundaries close to $45^{\circ}$ with the main tensile axis. 


$$
\tau_{\mathrm{PFZ}}=K_{\mathrm{PFZ}} \gamma_{\mathrm{PFZ}}^{{ }_{\mathrm{PFZ}}}+\tau_{\mathrm{c}, \mathrm{PFZ}}
$$

where $p_{\mathrm{PFZ}}$ is the strain hardening exponent in the PFZ and $K_{\mathrm{G}}$ is the strain hardening factor in the PFZ. Following Embury and Nes [27], the critical shear strain at which failure occurs in the PFZ is given by:

$$
\gamma_{\mathrm{PFZ}, \mathrm{c}}=0.5\left(f_{\mathrm{GB}}^{-0.5}-1\right)
$$

The total energy related to plastic deformation by shear is given by:

$$
\begin{aligned}
E_{p} & =E_{p, G}+E_{p, P F Z} \\
& \propto \frac{d_{G}}{d_{G}+d_{P F Z}}\left(\frac{1}{p_{G}+1} K_{\mathrm{G}} \gamma_{\mathrm{G}}^{p_{G}+1}+\tau_{\mathrm{c}, \mathrm{G}} \gamma_{\mathrm{G}}\right)+\frac{d_{P F Z}}{d_{G}+d_{P F Z}}\left(\frac{1}{p_{P F Z}+1} K_{\mathrm{PFZ}} \gamma_{\mathrm{PFZ}}^{p_{P F Z}+1}+\tau_{\mathrm{c}, \mathrm{PFZ}} \gamma_{\mathrm{PFZ}}\right)
\end{aligned}
$$

Inserting Eqs. 2-4 in Eq. 5, provides an expression for $E_{\mathrm{p}}$ at the stage where the failure process initiates in the case of a material under uniform strain. Whilst the test results here consider notched samples, i.e. with high stress concentration around the notch, we will assume that trends in measured fracture energies are related to $E_{\mathrm{p}}$ at the stage where grain boundaries ahead of the contiguous crack start to fail. We will term this $E_{\mathrm{p}, \text { crit. }} E_{\mathrm{p}, \text { crit }}$ defines a lower limit for $E_{\mathrm{p}}$ for the stage where the crack has progressed through the material. It is expected that $E_{\mathrm{p}}-E_{\mathrm{p} \text {,crit }}$ is much smaller than $E_{\mathrm{p}}$ and hence we can assume that $E_{\mathrm{p}, \text { crit }}$ is a reasonably good measure of the total energy consumed in crack progression. Under equi-shear stress conditions, e.g. $\tau_{\mathrm{G}}=\tau_{\mathrm{PFZ}}$, and if the materials parameters $\left(K, \tau_{\mathrm{c}}\right)$ and $f_{\mathrm{GB}}$ are known, all quantities in Eqs. 2-5 can be determined. These calculations have been implemented using measured and estimated parameters for 6156-T6 alloy sheet that was quenched in water at $60^{\circ} \mathrm{C}: f_{\mathrm{GB}}=0.09, d_{\mathrm{PFZ}}=80 \mathrm{~nm}$ (both from TEM data), $d_{\mathrm{G}}=20 \mu \mathrm{m}$ (from SEM observations), $\sigma_{\mathrm{y}, \mathrm{G}}=400 \mathrm{MPa}$ (from proof strength of $6156-\mathrm{T} 6$ ), $\sigma_{\mathrm{y}, \mathrm{PFZ}}=160 \mathrm{MPa}$ (estimated form the yield strength of $\mathrm{Al}-\mathrm{Mg}-\mathrm{Si}$ alloys with $\mathrm{Mg}+\mathrm{Si}$ content of about $1 \mathrm{at} \%$ in $\mathrm{T} 1$ condition). We further take $\tau_{\mathrm{y}, \mathrm{G}}=0.5 \sigma_{\mathrm{y}, \mathrm{G}}$ and $\tau_{\mathrm{y}, \mathrm{PFZ}}=0.5 \sigma_{\mathrm{y}, \mathrm{PFZ}}$. From earlier work on $\mathrm{Al}$ based alloys [26] we further estimate $p_{\mathrm{G}}=0.5, K_{\mathrm{G}}=150 \mathrm{MPa}$. We have no reliable data on $p_{\mathrm{PFZ}}$, and in a first approximation we will assume that any difference between $p_{\mathrm{PFZ}}$ and $p_{\mathrm{G}}$ is limited, i.e. $p_{\mathrm{PFZ}} \approx p_{\mathrm{G}}$.

The model reveals the underlying causes for changes in toughness and the microstructural parameters which affect these changes, with several of the results being different from hitherto published work. As anticipated, the strain in the PFZ at the grain boundary is much larger than that in the grain. For the present alloy there is about a factor 100 difference. However, for the present 
alloy, the total work due to plastic shear deformation is mostly stored in the grains (factor 10 difference). In fact, an analysis using estimates of the relevant parameters $\left(f_{\mathrm{GB}}, d_{\mathrm{PFZ}}, d_{\mathrm{G}}, \sigma_{\mathrm{y}, \mathrm{G}}, \sigma_{\mathrm{y}, \mathrm{PFZ}}\right.$, $\left.\tau_{\mathrm{y}, \mathrm{G}}, \tau_{\mathrm{y}, \mathrm{PFZ}}, p\right)$ for a range of $\mathrm{Al}$ based alloys which develop PFZs at grain boundaries, shows that this situation (work due to plastic deformation being mostly stored in grains), is common. Hence shear deformation of the grains contributes considerably more to toughness as compared to shear deformation of the PFZ. As a consequence, the plastic work for fracture is not proportional to $f_{\mathrm{GB}}{ }^{-0.5}$ as suggested by the Embury and Nes [27] approach; this proportionality is only valid if plastic work for deformation of grain is negligible compared to that in the PFZ. The influence of the different parameters on the plastic work for fracture was analysed by introducing small variations in the key model parameters. This showed that $d_{\mathrm{PFZ}}$ has a very limited influence: a $1 \%$ change in $d_{\mathrm{PFZ}}$ causes a $0.07 \%$ change in $E_{\mathrm{p}}$; but $f_{\mathrm{GB}}$ has a strong influence: $1 \%$ change in $f_{\mathrm{GB}}$ causes a $6 \%$ change in $E_{\mathrm{p}}$. $\sigma_{\mathrm{y}, \mathrm{PFZ}}$ has a very strong influence as it strongly influences the level of plastic deformation in the grain: $1 \%$ change in $\sigma_{\mathrm{y}, \mathrm{PFZ}}$ causes a $5 \%$ change in $E_{\mathrm{p}}$; and also $\sigma_{\mathrm{y}, \mathrm{G}}$ has a very strong influence: $1 \%$ change in $\sigma_{\mathrm{y}, \mathrm{G}}$ causes a $18 \%$ change in $E_{\mathrm{p}}$. As could be expected the work hardening in grain and PFZ have a significant influence on $E_{\mathrm{p}}$ : a $1 \%$ increase in both $K_{\mathrm{G}}$ and $K_{\mathrm{PFZ}}$ causes an increase in $E_{\mathrm{p}}$ of $6 \%$. The effect is stronger if the work hardening behaviours of grain and PFZ change differently, and in such a manner that they will compensate yield strength differences. So if $K_{\mathrm{PFZ}}$ increases by $1 \%$ and $K_{\mathrm{PFZ}}$ remains constant, then $E_{\mathrm{p}}$ increases by $8 \%$.

It should be noted that the present analysis provides predictions that are very different from some other published models analysing the influence of the PFZ and the grain boundary coverage on fracture energies. For instance, Li and Reynolds [28], using the approaches of Hornbogen and Gräf [1] and Kawabata and Izumi [3], indicated the following relation:

$$
K_{I C} \cong\left[\frac{E_{m} \sigma_{P F Z} d_{P F Z} \cdot \varepsilon_{f i}}{C d_{g}}\right]^{1 / 2}
$$

where $E_{\mathrm{m}}$ is the Young's modulus, $\sigma_{\mathrm{PFZ}}$ is the PFZ flow strength, $C$ is a constant and $\varepsilon_{f i}$ is the critical strain for the grain boundary. The latter equation assumes that the accommodation of bulk shear strain occurs within PFZs only, with local PFZ strains then decreasing with increasing PFZ width for a given grain size. This modelling approach predicts a strong increase in fracture toughness with an increase of the PFZ width, but our analysis indicates that this is not the case. Indeed apparently contradictory influences of PFZ width on fracture behaviour have been noted in the literature [22,26,29] and Unwin and Smith [26] have particularly demonstrated a negligible influence of PFZ widths between 100 and $600 \mathrm{~nm}$ on fracture toughness in ternary Al-Zn-Mg 
materials for a fixed proof stress and area fraction of boundary precipitates. (It is noted that grain boundary coverage was however quite high $(\sim 0.6)$.) The model of Dumont and co-workers [2] considers a sum of fracture energies for transgranular fracture and intergranular fracture that are weighted by the area fractions on the fracture surfaces and intergranular fracture is assumed to occur without the influence of shear. As discussed above, the latter appears to be incompatible with the SRCT observations for our samples in the lower stress triaxiality fracture region.

Whilst it is admittedly a simplified model, our new equi-shear-stress model can explain the observation that is crucial in applications: the decrease in propagation energy on reducing the severity of the quench to a quench in water at $60^{\circ} \mathrm{C}$. The TEM experiments have shown some changes in PFZ size on reducing the severity of the quench to a quench in water at $60^{\circ} \mathrm{C}$, but the model clearly shows that this should not influence the propagation energy. The grain boundary coverage, which is difficult to measure accurately, seems to increase somewhat on reducing the severity of the quench to a quench in water at $60^{\circ} \mathrm{C}$, and this can be a significant factor in the observed reduction in the propagation energy. Apart from this geometrical factor, the model also identifies the combination of yield strength and work hardening of the PFZ as important factors. Eq. 5 indicates that the term $\tau_{\mathrm{c}, \mathrm{PFZ}} \gamma_{\mathrm{PFZ}}+K_{\mathrm{PFZ}} \gamma_{\mathrm{PFZ}}^{p_{\mathrm{PFZ}}+1} /\left(p_{P F Z}+1\right)$ describes the combined effect of work hardening parameters and yield strength of the PFZ, and the sensitivity analysis above showed that for our alloy yield strength and work hardening variations both cause significant changes in toughness. The yield strength of the PFZ can indeed vary significantly with quenching condition as the amount of co-clusters, which were identified by DSC [23], will depend strongly on any solute depletion in the PFZ, which in turn will have a very strong influence on local strength [30]. It is known that $\mathrm{Cu}$ and $\mathrm{Mg}$ content of the Al-rich phase can have some influence on work hardening factor $K$ [31] and thus also changes in work hardening of the PFZ can influence the toughness significantly. (Note that the term $\tau_{\mathrm{c}, \mathrm{PFZ}} \gamma_{\mathrm{PFZ}}+K_{\mathrm{PFZ}} \gamma_{\mathrm{PFZ}}^{p_{P F Z}+1} /\left(p_{P F Z}+1\right)$ indicates that if the grain

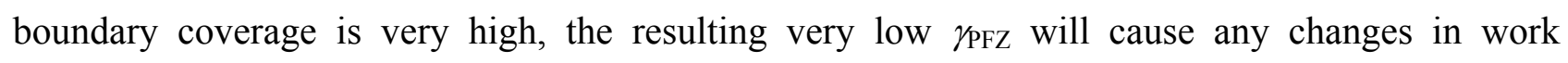
hardening to have a limited effect on toughness in comparison with changes in the yield strength of the PFZ. In such a case the yield strength of the PFZ is the determining factor, and the alloy will be extremely embrittled.)

Whilst the new model is successful in semi-quantitatively analysing the fracture at grain boundaries, it seems that in order to fully understand the fracture processes in the present materials an appropriate multimechanistic micromechanical model is required which would ideally account for the stress triaxiality influence on fracture modes and would also consider the different fracture initiation mechanisms. 


\section{Conclusions}

Kahn tear tests and microstructural analysis were performed on 6156 samples which were quenched at different rates and subsequently artificially aged.

- Both the coverage of grain boundary decoration and PFZ width increase with changing water quench temperature from $20^{\circ} \mathrm{C}$ to $60^{\circ} \mathrm{C}$. Heterogeneous precipitation on dispersoids and PFZ formation around the dispersoids occurred in the air cooled material.

- The crack propagation energy is substantially reduced as a result of changing water quench temperature from $20^{\circ} \mathrm{C}$ to $60^{\circ} \mathrm{C}$. However, the crack initiation energy in high stress triaxiality condition seems less affected by the slower water quench, indicating an increased sensitivity of lower stress triaxiality failure to changes in grain boundary character.

- SEM and micro-computed tomography studies of arrested crack tips of samples before and after gallium wetting revealed the following quench effects:

o $60^{\circ} \mathrm{C}$ water quenched material: comparison of the main crack before and after gallium wetting shows that much of the crack is intergranular in nature. The crack tip has a ligamented morphology and consists of coarse voids and areas of narrow opening that are inclined with respect to the loading direction. Those areas have been identified to lie on grain boundaries.

o $20^{\circ} \mathrm{C}$ water quenched material: cracking of the $20^{\circ} \mathrm{C}$ water quenched material mainly consists of coarse voids and areas of shear decohesion. The crack tip is hardly ligamented and only very few independent crack initiation sites are seen away from the main crack.

o Air cooled material: in the air cooled material the crack appears to be fully intergranular, few coarse voids are present and the crack opening is very narrow. Substantially fewer independent GB crack initiation sites are seen compared to the $60^{\circ} \mathrm{C}$ water quenched material, i.e. there is relatively little damage evolution prior crack coalescence.

- A simple model based on an equi-shear-stress assumption is derived. It shows the dominant influence of grain boundary coverage and yield strength of the PFZ on propagation energy. For most Al based alloys PFZ width has little influence on the propagation energy.

\section{Acknowledgements}


The authors would like to acknowledge Alcan CRV for financial support and material supply, and Frederic Bron and Bernard Bes for technical discussion. We would also like to thank Jean-Yves Buffière for support in micro-computed tomography.

\section{References}

[1] Hornbogen E, Gräf M. Acta Metall 1977; 25: 877-881

[2] Dumont D, Deschamps A, Brechet Y. Acta Mater 2004; 52: 2529-2540

[3] Kawabata T, Izumi O. Acta Metall 1976: 24; 817-825

[4] Morgeneyer TF, Starink MJ, Sinclair I. Acta Mater Acta Materialia, 2008; 56, 1671-1679

[5] Maire E, Buffiere J-Y, Salvo L, Blandin JJ, Ludwig W, Letang JM. Adv Eng Mater 2001; 3 : 539-546

[6] Dif R, Bès B, Ehrström JC, Sigli C, Warner TJ, Lassince Ph, Ribes H. Mater Sci Forum 2000; 331-337: 1613-1618

[7] Rometsch PA, Starink MJ, Gregson PJ. Mater Sci Eng A 2003; 339: 255-264

[8] Morere B, Ehrström JC, Gregson PJ, Sinclair I. Metall Trans A 2000; 31: 2503-2515

[9] Shuey RT, Tiryakioglu M, Bray GH, Staley JT. Mater Sci Forum 2006; 519-521: 1017-1022

[10] Morita S, Toda H, Takahashi A, Hoshiyama A, Kobayashi T, Nagashima H. J Jpn Inst Light Met 2001;51:307-312

[11] De Haas M, De Hosson JTM. J Mater Sci 2002 ; 37 : 5065-5073

[12] Bratland DH, Grong Ø, Shercliff H, Myhr OR, Tjøtta S. Acta Mater 1997;45: 1-22

[13] Rometsch PA, Wang SC, Harriss A, Gregson PJ, Starink MJ. Mater. Sci. Forum 2002; 396402: 655-660

[14] Hatch JE. Aluminum: properties and physical metallurgy. Metals Park, OH: ASM; 1984.

[15] ASTM-international, Standard Designation B 871 - 01. 2001: West Conshohocken, USA

[16] Kocsis M, Snigirev A. Nucl Instrum Methods Phys Res Sect A 2004; 525A: 79-84

[17] Ludwig W. Dissertation der LMU München, München, 2001

[18] Ludwig W, Bellet D. Mater Sci Eng A 2000; 281: 198-203

[19] Tanaka M, Warner T. Mater Sci Forum 2000; 331-337: 983-988

[20] Knott JF. Fundamentals of Fracture Mechanics. London: Butterworth; 1973

[21] Bron F, Besson J, Pineau A. Mater Sci Eng A 2004 ; A 380 : 356-364

[22] Vasudevan AK, Doherty RD. Acta Metall 1987; 35 : 1193-1219

[23] Morgeneyer TF, Starink MJ, Sinclair I. Mater Sci Forum 2006; 519-521: 1023-1028

[24] Dumont D, Deschamps A, Brechet Y. Mat Sci Eng A 2003; 356: 326-336

[25] G. Lutjering, A. Gysler. Proc. 1st Int. Conf. On Aluminium, Argentina (1978) published as Aluminium Transformation Technologies and Applications (edited by C. A. Pampillo, H. Biloni and J. D. Embury), p.171. Am. Soc. Metals, Ohio (1980)

[26] Unwin PT, Smith GC. J Inst Metals 1969; 97: 299-310

[27] Embury JD, Nes E. Z Metallkd 1974; 65: 45-55

[28] Li BQ, Reynolds AP. J Mater Sci 1998; 33: 5849-5853

[29] Kamp N, Sinclair I, Starink MJ. Metall Mater Trans A 2002 ;33A : 1125-1136.

[30] Starink MJ, Gao N, Davin L, Yan J, Cerezo A. Phil. Mag., 2005; 85: 1395-1418.

[31] Zhu Z, Starink MJ, Mater Sci Eng A, 2008, [in press], doi:10.1016/j.msea.2007.12.019. 